\title{
Article \\ The Pilot Study of the Hazard Perception Test for Evaluation of the Driver's Skill Using Virtual Reality
}

\author{
Tatsunori Sawada ${ }^{1, *(\mathbb{D}, \text { Hiroki Uda }}{ }^{2}$, Akira Suzuki $^{3}$, Kounosuke Tomori $^{1}{ }^{1}$, Kanta Ohno ${ }^{1}$, Hiroki Iga ${ }^{4}$, \\ Yuho Okita ${ }^{5}$ and Yoshio Fujita ${ }^{6}$ \\ 1 Major of Occupational Therapy, Department of Rehabilitation, School of Health Sciences, \\ Tokyo University of Technology, Ohta-ku, Tokyo 144-8535, Japan; tomoriks@stf.teu.ac.jp (K.T.); \\ ohnoknt@stf.teu.ac.jp (K.O.) \\ 2 Saitama Misato Rehabilitation Hospital, Misato, Saitama 341-0024, Japan; h4117007ad@edu.teu.ac.jp \\ 3 Funabashi Municipal Rehabilitation Hospital, Funabashi, Chiba 273-0866, Japan; h41160207f@edu.teu.ac.jp \\ 4 IMS Itabashi Rehabilitation Hospital, Itabashi-ku, Tokyo 174-0051, Japan; fhuuu.wp@gmail.com \\ 5 Soaring Health Sports Wellness \& Community Centre, Thomastown, VIC 3074, Australia; \\ y.okita.griffith@gmail.com \\ 6 Department of Rehabilitation, Chiba Prefectural University of Health Sciences, Mihama-ku, \\ Chiba 261-0014, Japan; yoshio.fujita@cpuhs.ac.jp \\ * Correspondence: sawadatn@stf.teu.ac.jp; Tel.: +81-3-6424-2148
}

check for updates

Citation: Sawada, T.; Uda, H.; Suzuki, A.; Tomori, K.; Ohno, K.; Iga, H.; Okita, Y.; Fujita, Y. The Pilot Study of the Hazard Perception Test for Evaluation of the Driver's Skill Using Virtual Reality. Electronics 2021, 10, 1114. https://doi.org/10.3390/ electronics10091114

Academic Editors: Antonino Naro and Rocco Salvatore Calabrò

Received: 24 March 2021

Accepted: 3 May 2021

Published: 8 May 2021

Publisher's Note: MDPI stays neutral with regard to jurisdictional claims in published maps and institutional affiliations.

Copyright: (c) 2021 by the authors. Licensee MDPI, Basel, Switzerland. This article is an open access article distributed under the terms and conditions of the Creative Commons Attribution (CC BY) license (https:// creativecommons.org/licenses/by/ $4.0 /)$.

\begin{abstract}
Background: Although various technologies are used to evaluate driving skill, there are some limitations such as the limited range of the monitor and the possible risk of causing cybersickness. The purpose of this study is to investigate differences in the hazard perception and cybersickness experienced between novice and experienced drivers measured in a VR hazard perception test with a head-mounted display (HMD). Methods: The novice $(n=32)$ and the experienced drivers $(n=36)$ participated in the hazard perception test through the VR of an HMD. Results: The total number of identified hazards was 1071 in the novice drivers and 1376 in the experienced drivers. Two of the hazards appeared to be only identifiable through the HMD. A chi-square test revealed that experienced drivers were more likely to identify the hazards than the novice drivers $(p<0.05)$. The novice drivers appeared to identify "hazard prediction of the current behavior of other road users" more than other hazard types, unlike the experienced group. The Simulator Sickness Questionnaire scores indicated no significant difference in the different age or gender groups $(p>0.05)$. Conclusion: Our results suggest that the VR hazard perception test may be useful for evaluating patients' driving skills.
\end{abstract}

Keywords: virtual reality; head-mounted display; driving; hazard perception; virtual reality sickness

\section{Introduction}

Driver evaluation is an important area in occupational therapy, and this has been used to evaluate the driving skill of various subjects such as those who have had a stroke and aged people. Although the on-road test is still considered the gold standard of driving evaluation [1], many studies support off-road assessments such as neuropsychological tests and driving simulators for evaluating driving skills [2,3].

The important aim of driver evaluation is to identify the risk of drivers' accidents and violations accurately. Hazard perception, which is defined as situation awareness for dangerous situations in the traffic environment [4], is one of the essential driving skills because a previous study revealed that hazard perception has the highest correlation with traffic accidents among the other driving skills [5]. A previous study showed that a driver's limited hazard perception is directly linked to increased traffic accidents, whereas sufficient hazard perception could help avoid the risk of traffic accidents [4]. Other studies clarified that hazard perception can be improved with driving experience. Furthermore, the hazard type identified by novice drivers appeared to be different from the experienced 
drivers $[6,7]$, and experienced drivers can identify higher numbers of hazards than novice drivers $[6,8]$. In addition, experienced drivers seem to be able to respond to hazards faster than novices $[6,9]$. A recent systematic review revealed that the hazard perception test is a practical evaluation to distinguish novice from experienced drivers [10].

The evaluation of hazard perception is an important area to be completed in clinical practice. Among the various driving tests in rehabilitation, the hazard perception test, the useful field of view test, and the Multi-D battery are recommended driver's tests in Australia in terms of their high reliability and high level of evidence [11]. A previous study that included subjects with hemianopia showed that a significant number of subjects could not identify hazards on their blind side [12]. Sasaki et al. [13] conducted a hazard perception test using tablets, showing that subjects who had a stroke provided significantly lower scores and reaction times than healthy individuals. A previous study concluded that the hazard perception test helps evaluate for higher brain function (e.g., attention function, visuospatial agnosia, and hemianopia), especially the ability to identify the hazard in the spread view field.

The hazard perception test is a critical element in driving as driving requires skills to manage different hazards such as pedestrians, drivers, and different traffic situations. Since drivers need to be aware of obvious or hidden hazards in traffic situations, situation awareness to detect possible hazards and make decisions is necessary for driving [4] Sensory awareness theory supports the importance of the hazard perception test as well as situation awareness skill.

Situation awareness theory is the model that humans make a decision based on a combination of individual factors and the perception of elements in the current situation (Level 1), comprehension of the current situation (Level 2), and perception of future status (Level 3) (please refer to Figure 1) [14,15]. Therefore, it is important to identify whether the hazard perception test can show the actual driving situation or not. It is essential to establish and implement the hazard test in which the subject can feel like they are driving on the road. Hazard perception is usually evaluated by showing a video to the participants $[6,8,9]$. Virtual reality (VR), such as video clips, is useful for facilitating situation awareness. The virtual environment can create presence, which is a state of consciousness, the (psychological) sense of being in the virtual environment [16,17]. This sense is useful for conducting a hazard perception test because it allows the subject to feel like they are driving on the road.

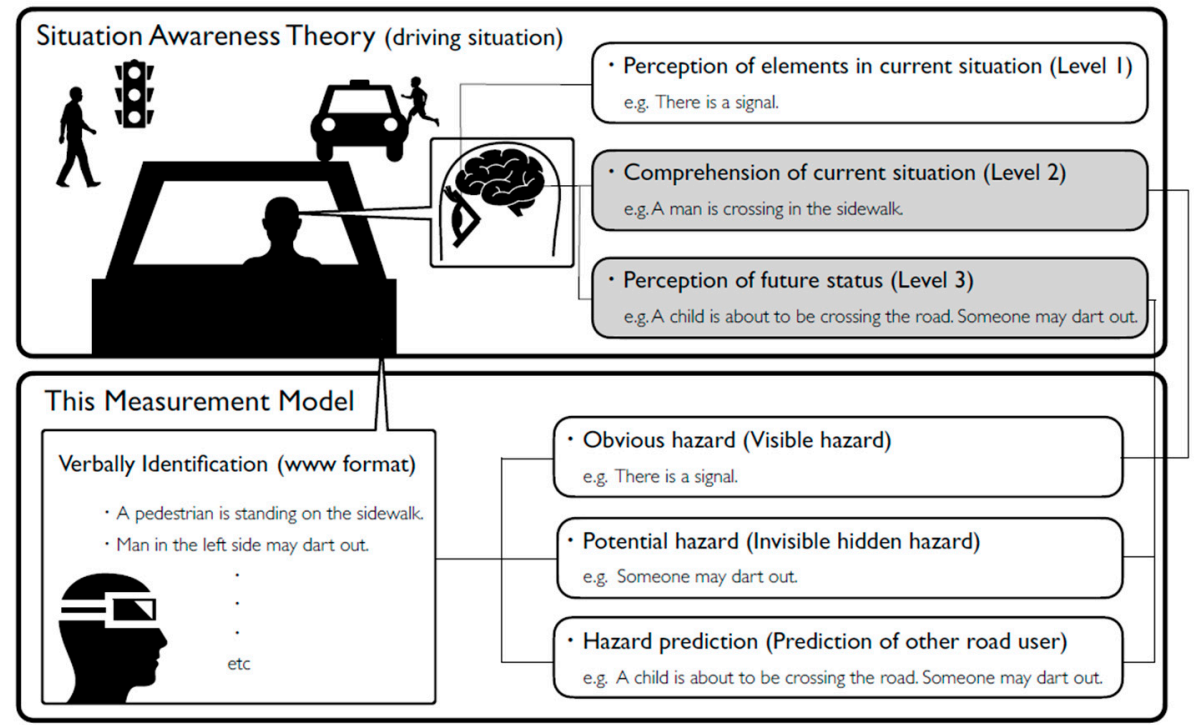

Figure 1. Situation Awareness Theory and measurement model in this study.

However, there are still some limitations in that subjects only have a limited visual field through the limited range of the monitor view because the hazard perception tests 
in previous studies were conducted over a personal computer or tablet $[6,8,9,12,13]$. In order to drive any vehicle safely, it is vital to ensure extensive visual confirmation with rotation of the neck and trunk to check the lateral and posterior sides of the vehicle. From the point of view of situation awareness, whether to show the actual traffic situation is an essential factor in the hazard perception test, and it is assumed that the visual limitation of the size of the monitor is the weak point of the hazard perception test $[18,19]$. Using VR with a head-mounted display (HMD) could be an effective method to address this concern as an HMD can easily stream 360-degree movies and images, and low prices of HMDs are currently available, meaning that they can be used in clinical practice. One of the main characteristics of VR is that the user can experience a reproduced real-world virtually, and this allows them to have a sense of self-location within it by moving their head and eyes [20]. An HMD, which is an important component of VR, allows users to facilitate a sense of "being there", which helps them feel like they are in the real world [20].

VR technology is useful in driving rehabilitation as this allows users to experience driving situations safely by reproducing the same traffic condition regardless of the administration time, unlike the on-road test [21]. Furthermore, it is cognitively challenging to apply information acquired through PC-based hazard perception to an actual driving situation [18,22]. Hazard perception training using an HMD significantly improved novice drivers' hazard perception [22]. We believe developing a driving evaluation using an HMD may be a useful evaluation in rehabilitation in terms of this feature. However, there are only a few studies about hazard perception training using VR with an HMD [18,19], and no study has investigated the hazard perception test using VR with an HMD yet.

On the other hand, one of the limitations of an HMD is the possible risk of cybersickness, which can cause some symptoms such as headache and nausea. There are several terms for this condition: motion sickness, simulator sickness, and virtual reality sickness; we use the same terminology, "cybersickness", in this study. It is commonly seen that viewing images or movies of driving (e.g., driving simulator) can easily cause cybersickness. A previous study showed that $37 \%$ of participants who had a stroke dropped out of the study due to cybersickness [23]. A study of hazard perception training using an HMD revealed that $13 \%$ of participants dropped out for cybersickness [19]. Classen et al. [24] also suggested that aged people and females tend to get cybersickness. These results were collected by viewing the monitor on either one or three screens, but an HMD appeared to cause more severe sickness among the participants $[25,26]$. A systematic review showed that cybersickness in a driving simulator cannot be avoided with the current technology and still causes discomfort to users [27].

Although some theories explain the causes of cybersickness, sensory conflict theory would be the most promising theory to be applied. Motion sickness, like cybersickness, can be caused by a conflict between different sensory stimuli (visual, vestibular proprioceptors) and a difference in expectations from the previous experience $[27,28]$. The sensory conflict is commonly caused by the mismatch between the visual and vestibular sensations (sensory conflict theory) [28]. Cybersickness and motion sickness can cause the same symptoms. However, cybersickness only occurs from visual sensation without vestibular sensation [29]. This phenomenon can be explained by vection. Vection is the important factor of cybersickness and a misleading impression of self-motion [29]. Vection arises even if the person is in a stationary position. An optical flow such as a driving video causes vection [29,30]. A previous study demonstrated that driving simulation had many stimulus cues to cause vection $[29,31]$. This visual sensation without motion and the vestibular system follows the concept of sensory conflict theory. These sensory conflicts arise when the subject experiences the stimulus they were not expecting to receive. In regard to cybersickness, the virtual environment needs to be carefully considered in the driving simulator. In the simulation, the subject experiences a sense of vection as the given optical flow patterns of the road, buildings, and other parts of the environment move past the subject's periphery. The subject receives various pieces of visual information including a pedestrian moving in a particular direction, and a car accelerating when pressing the gas pedal and decelerating 
when pressing the brake. However, since the subject is not moving, the vestibular sense provides no sense of linear or angular acceleration or deceleration, which will cause the subject to experience cybersickness from the sensory conflicts. Previous studies showed that the user experiences more severe cybersickness with increased exposure time with an HMD [32]. This finding indicates that prolonged exposure to VR accumulates sensory conflict, finally causing cybersickness. Therefore, we hypothesized that cybersickness could be reduced by avoiding differences and conflicts generated from multiple sensory inputs and with less exposure time. Since the hazard perception test is to watch a driving scene, we believe that cybersickness can be controlled by minimizing the duration of the hazard perception test video.

\section{Problem Statement and Objectives}

This study aimed to explore the potential of VR with an HMD as an empirical research tool in psychological and architectural research. As stated above, there is no research about the hazard perception test using VR with an HMD yet, so we conducted this pilot study for the development of hazard perception tests using VR concerning the following two points:

(1) To verify the difference in hazard perception between novice and experienced drivers in the VR hazard perception test;

(2) To investigate the effect of cybersickness in the VR hazard perception test.

This study was completed with a practice-oriented research approach in which the research objectives were developed from the current concern in health practice and needs from a health professional point of view.

\section{Materials and Methods}

\subsection{Subject}

Inclusion criteria were subjects who have a driver's license without a cognitive and physical history. Participants in the novice group were in their 20s who had just obtained a driver's license, and participants in the experienced group were in their 30 s to 50 s who had driving experience of more than ten years. The participants in the novice group were recruited from the occupational therapy students at the Tokyo University of Technology, and those of the experienced group were staff in the IMS Itabashi Rehabilitation Hospital. They were informed about this research by email, and participants contacted the research team and were introduced to the research in detail. This study was performed in accordance with the Declaration of Helsinki and was approved by the ethics committee of Tokyo University of Technology (No. E19HS-013). A written informed consent was obtained from each participant prior to participating in this research.

\subsection{Hazard Perception Scenario}

For developing the hazard perception test, a 360-degree camera (THEATA V, RICO Inc, Ontario, CA, USA) was fixed in the driver's seat of the motor vehicle (NISSAN, Serena), and the actual driving scene was recorded in $4 \mathrm{~K}$ video mode. The captured videos about potential dangerous scenes were extracted by two experts (TS, YF) who had more than 20 years of experience in driving occupational therapy. Potential hazards were shown in the scenes included as follows: other road users such as intersections with poor visibility and pedestrians; those with in-vehicle TV and audio as disturbance stimuli; and those with pedestrians (Supplementary Materials file A). The video was edited with software (Final Cut Pro, Apple Inc., Cupertino, CA, USA) and exported to be a 360-degree video with full $\mathrm{HD}$ as a hazard perception test. We inserted two practice exercise videos with an explanation to promote the understanding of participants at the beginning of the hazard perception test. The test consisted of 15 scene scenarios, and the total time was $14 \mathrm{~min}$ (including two practice exercises). Each question section was about $40 \mathrm{~s}$, consisting of $20 \mathrm{~s}$ of a driving scene video and $20 \mathrm{~s}$ of showing the images (Figure 2, Video S1; see the Supplementary Materials file). The subject was requested to identify the hazard while the 
image was shown (for $20 \mathrm{~s}$ ). There was a rest period when the question number (question 1 , etc.) was presented for $5 \mathrm{~s}$ on a black screen between each question.
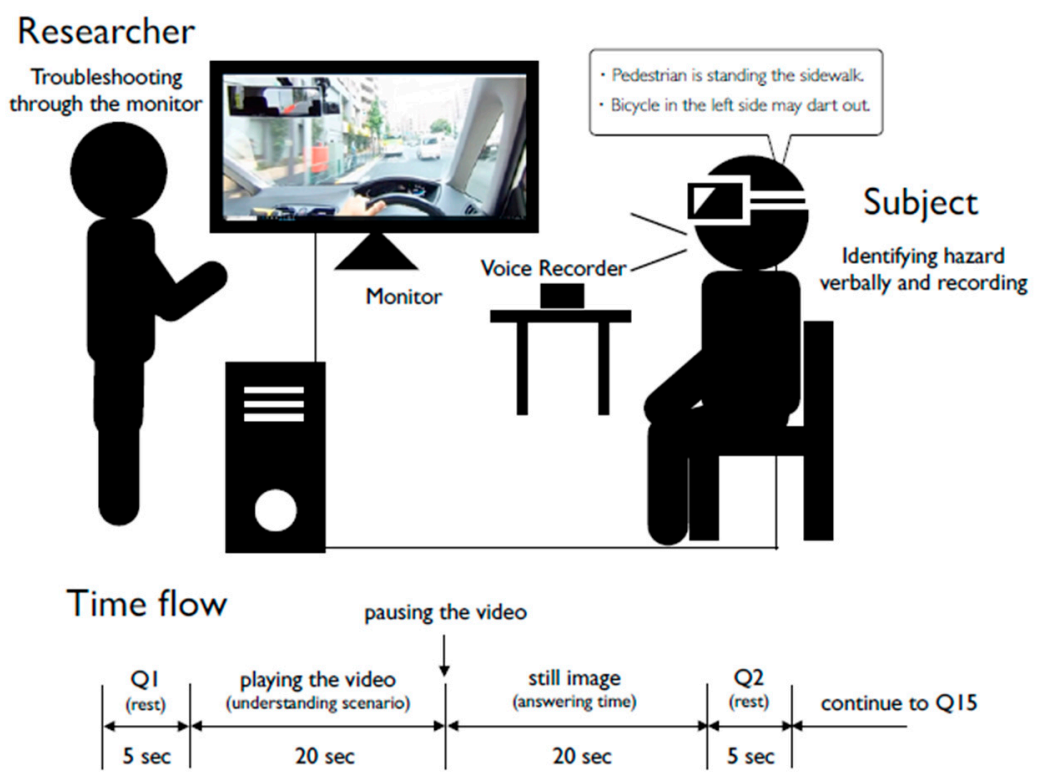

Figure 2. Experimental procedure.

\subsection{Hazard Types}

A systematic review showed that there were considerable differences in the scenario type [10]. Although many studies did not strictly classify the hazard type, there was agreement that potential and hidden hazardous events are more important than visible and obvious hazards, and these hazards were characterized between novice and experienced drivers $[4,6,8,9,13,19,33]$. The classification of hazard type as a framework is useful for hazard perception test development [10]. Therefore, the classification of hazard type is necessary for a pilot study to verify the difference in hazard perception, like the current study. Renge et al. [34] classified hazards into three types: obvious hazards, hazards relating to the prediction of other road users, and potential hazards hidden in blind spots. Crundall et al. [35] classified hazard types differently as follows: behavioral hazard predicting future behavior directly from current behavior; environmental hazard with two different stimuli occurring simultaneously; and divided and focused attention. Borowsky et al. [36] also classified three types: (1) materialized hazards, which require an evasive response, (2) hidden unmaterialized hazards, which are potential sources of danger, and (3) potential unmaterialized hazards, which are visible sources of danger but do not materialize. The concepts of these hazard types appear to be similar to obvious hazards, materialized hazards, behavioral hazards, hazards relating to the prediction of other road users, and potential unmaterialized hazards. On the other hand, an environmental hazard is difficult to be recorded because it does not frequently occur during everyday driving. Staged hazards and intentionally created hazards possibly have some biases because a creator who is an experienced driver may create scenes that favor individuals [8]. Therefore, in this study, the following unstaged hazard types were defined with reference to these concepts (Table 1). These hazard type classifications are consistent with sensory awareness theory. For example, $\mathrm{OH}$ means a visible hazard that does not predict behavior, and it is consistent with Level 2. In addition, PH and HP match Level 3 because the previous situation must be predicted. 
Table 1. The definition of hazard types in this study.

\begin{tabular}{ll}
\hline Obvious hazard $(\mathrm{OH})$ & Visible hazard \\
\hline Potential hazard $(\mathrm{PH})$ & Invisible hidden hazard \\
\hline Hazard prediction $(\mathrm{HP})$ & $\begin{array}{l}\text { Hazard prediction of current behavior of other } \\
\text { road users }\end{array}$ \\
\hline
\end{tabular}

\subsection{Procedure}

Prior to the hazard perception test, the researchers explained it to the subjects on paper, and the participants confirmed the experimental rule, such as answering about the hazard verbally or pointing out the hazard accurately by using a picture (about $5 \mathrm{~min}$ ). Subsequently, the subject was seated on a chair and wore an HMD (HTC VIVE, resolution $2160 \times 1200,1080 \times 1200$ per eye, 90 FPS), which provided 110 degrees of field of view with sound via headphones, connected to a personal computer (Diginnos GALLERIA; Core i7-7700K 4.20GHz/8GB/GTX 1060 6GB). The researcher adjusted the driver seat as well as verbally prompting the subject to maintain the right posture. This adjustment was to allow their field of view to be similar to the actual driving situation confirmed through the monitor. The subjects then watched a video of the hazard perception test. At first, the subject watched two practice exercise scenarios about the test. After that, they conducted the hazard perception test (15 scenarios). One video scenario was shown for $20 \mathrm{~s}$; after, the video was paused (image). The subject verbally identified hazards in the image (20 s).

Various methods have been utilized in the detection of the hazard perception test. One of the methods is that the users are required to press a button for measuring the response time, which can be improved with experience [37]. However, this method does not detect the spatial location of the hazard (e.g., where the hazard is identified). Another method, which requires the user to touch or click the screen for the measurement, can detect both the spatial location and the response time. Both of these methodologies can allow scoring by preparing the answers in advance [7,12]. However, this study is a pilot study requiring the collection of data of answers for future study, meaning that this study did not include any of the methods mentioned above. This research was completed following the WWW format, which requires the participants to verbally identify what happens next in the hazard perception test and where it happens. Although this method cannot measure response time, the WWW format developed following the situation awareness framework is often used in studies of various hazard perception tests [14,15]. The validity and reliability of the WWW format in the hazard perception test have been ensured through previous studies $[10,14,15]$. The free answering question in the hazard perception test could distinguish experienced from novice drivers [38]. Since this study is a pilot study, an investigation of hazards needs to be conducted comprehensively, considering different types in different scenarios. Following the WWW format, this study's participants were asked to answer the questions verbally.

The subject was asked to identify 15 different scenarios verbally. During the hazard test, the oral answers were recorded with a voice recorder. A Simulator Sickness Questionnaire (SSQ) was immediately conducted after performing the hazard perception test. The SSQ, developed by Kennedy et al. [39], is a tool for assessing the severity of cybersickness symptoms. The SSQ consists of 16 items which are measured on a scale of 48 points in 4 stages (0 to 3) (Table 2). 
Table 2. Simulator Sickness Questionnaire.

\begin{tabular}{lccccc}
\hline & & $\mathbf{0}$ & $\mathbf{1}$ & $\mathbf{2}$ & $\mathbf{3}$ \\
\hline 1 & General discomfort & None & Slight & Moderate & Severe \\
2 & Fatigue & None & Slight & Moderate & Severe \\
3 & Headache & None & Slight & Moderate & Severe \\
4 & Eye strain & None & Slight & Moderate & Severe \\
5 & Difficulty focusing & None & Slight & Moderate & Severe \\
6 & Increased salivation & None & Slight & Moderate & Severe \\
7 & Sweating & None & Slight & Moderate & Severe \\
8 & Nausea & None & Slight & Moderate & Severe \\
9 & Difficulty concentrating & None & Slight & Moderate & Severe \\
10 & Fullness of the head & None & Slight & Moderate & Severe \\
11 & Blurred vision & None & Slight & Moderate & Severe \\
12 & Dizzy (eyes open) & None & Slight & Moderate & Severe \\
13 & Dizzy (eyes closed) & None & Slight & Moderate & Severe \\
14 & Vertigo & None & Slight & Moderate & Severe \\
15 & Stomach awareness & None & Slight & Moderate & Severe \\
16 & Burping & None & Slight & Moderate & Severe \\
\hline
\end{tabular}

\subsection{Data Analysis}

The recorded audio data were transcribed verbatim. After careful review of the interview transcript conducted by two researchers (TS, HU) independently, the contents of the hazard identified were labeled. The final decision of the label was decided through discussions. We consulted other researchers (KT, YF) about the labeling if required. A label was assigned to each hazard (the motor vehicle on the left may move, something may dart out from the right, etc.). After that, the number of subjects who selected the same label for each question was extracted, and the value obtained by dividing the number of selections by all the subjects was calculated (selection rate). Inclusion criteria of the hazard label in the novice or experienced group were set at more than $10 \%$ of the selection rate. Additionally, two researchers (TS, HU) qualitatively checked whether any crucial hazards did not match the criteria.

All hazard labels (hazardous events) that met the inclusion criteria were considered variables in this study, and they were examined using a chi-square test between the novice and experienced groups. Each hazard type $(\mathrm{OH}, \mathrm{PH}, \mathrm{HP})$ was also examined in the same way after. We also conducted a chi-square test to clarify the distribution of three hazard types within each group. If there was a significant difference in all analyses, a residual analysis was conducted. For cybersickness, the Mann-Whitney U test was used to compare SSQ values between genders or ages. All statistical analyses were performed with SPSS 24.0 with a significance level of $5 \%$.

\section{Results}

\subsection{Participants}

A power analysis using G-power revealed a requisite sample size of 47 (with an effect size of 0.52 , significance level of $p<0.05$, and power of 0.95 ). However, we recruited more than 47 in case the participants were not able to complete this experiment because of cybersickness. Finally, 68 participants, 32 novice drivers (13 males, 19 females, with an average age of 21.5 , SD 0.5 years) and 36 experienced drivers ( 24 males, 12 females, with an average age of $36.9, \mathrm{SD} 7.3$ years), participated in the study (Table 3$)$. There was no difference in the male/female ratio between novice and experienced drivers $\left(\chi^{2}(1)=2.770\right.$, $p=0.096$ ). The average years of driving history were 2.3 years (SD 0.8) in the novice drivers and 17.2 (SD 7.9) in the experienced drivers. There were no participants who stopped participating in this study. 
Table 3. Demographic data of subjects.

\begin{tabular}{|c|c|c|c|}
\hline & & Novice Group & Experienced Group \\
\hline \multicolumn{4}{|l|}{ Participants } \\
\hline Male & & 13 & 24 \\
\hline Female & & 19 & 12 \\
\hline Total & & 32 & 36 \\
\hline \multicolumn{4}{|l|}{ Age } \\
\hline Average & & 21.5 & 36.9 \\
\hline $\mathrm{SD}$ & & 0.5 & 7.3 \\
\hline \multicolumn{4}{|l|}{ Driving Experience } \\
\hline Average & & 2.3 & 17.2 \\
\hline $\mathrm{SD}$ & & 0.8 & 7.9 \\
\hline \multicolumn{4}{|l|}{ Hazard Identification } \\
\hline \multicolumn{4}{|c|}{ Hazard type } \\
\hline & Total & 79 & 82 \\
\hline & $\mathrm{OH}$ & 38 & 39 \\
\hline & $\mathrm{PH}$ & 17 & 19 \\
\hline & $\mathrm{HP}$ & 24 & 24 \\
\hline \multicolumn{4}{|c|}{ Indication number } \\
\hline & Total & 1071 & 1376 \\
\hline & $\mathrm{OH}$ & 547 & 690 \\
\hline & $\mathrm{PH}$ & 329 & 353 \\
\hline & $\mathrm{HP}$ & 195 & 333 \\
\hline
\end{tabular}

\subsection{Comparing the Hazardous Events and Type between Novice and Experienced Groups}

As a result of the analysis, 112 hazardous events were identified in each group, and 128 of them were obtained when both groups were combined. The total number of hazardous events identified by subjects was 1120 in the novice group and 1512 in the experienced group. Hazards which met the inclusion criteria totaled 82 events (79 in the novice group, 82 in the experienced group). The hazardous events were then categorized as follows: (1) OH: consisting of 39 hazardous events (38 in the novice group and 39 in the experienced group); (2) PH: consisting of 19 hazardous events (17 in the novice group and 19 in the experienced group); (3) HP: consisting of 24 hazardous events (24 in both groups) (Supplementary Materials file B). All hazardous events were classified into three types.

The total number of identified hazardous events that met the inclusion criteria was 1071 (OH 547, HP 329, PH 195) in the novice group and 1376 (OH 690, HP 353, PH 333) in the experienced group. Two of the hazardous events appeared to be only identifiable through the HMD: h11-5, pedestrian may run out into the street from the park, and h-12-2, motorcycles are approaching near the vehicle from the rear on the right side.

\subsection{Statistical Analysis between Two Groups}

A chi-square test was calculated comparing the number of $\mathrm{OH} / \mathrm{PH} / \mathrm{HP}$ hazard type identifications between novice and experienced groups. A significant interaction was found $\left(\mathrm{OH}: \chi^{2}(1)=7.193, p=0.008, \mathrm{PH}: \chi^{2}(1)=36.756, p=0.000, \mathrm{HP}: \chi^{2}(1)=11.283\right.$, $p=0.001)$. Experienced drivers were more likely to identify the hazard than the novices. In addition, a chi-square test was calculated comparing each identified hazard between the novice and the experienced group. The result shows that 18 hazards $(22.0 \%)$ had a significant difference, and five types (15.3\%) were $\mathrm{OH}$, seven types were $\mathrm{PH}(36.8 \%)$, and five types were HP (20.8\%) in each type (Table 4$)$. The novice group showed higher values than the experienced group for only two hazards (OH2-4, 4-4), and the experienced group had higher values than the novice group in all other hazards. 
Table 4. Hazard contexts which had significant differences by a chi-square test.

\begin{tabular}{|c|c|c|c|c|c|c|c|c|c|c|c|c|}
\hline & \multirow[t]{2}{*}{ HE } & \multirow[t]{2}{*}{ Hazard Context } & \multirow[t]{2}{*}{ HT } & \multicolumn{3}{|c|}{ Identification Number } & \multicolumn{3}{|c|}{$\begin{array}{l}\text { The Ratio of } \\
\text { Identification }\end{array}$} & \multirow[t]{2}{*}{$x^{2}$} & \multirow[t]{2}{*}{$p$-Value } & \multirow[t]{2}{*}{$\varphi$} \\
\hline & & & & NV & EX & Total & NV & EX & total & & & \\
\hline \multirow{3}{*}{ Q2 } & h2-2 & $\begin{array}{l}\text { A motor vehicle running } \\
\text { in the right side lane may } \\
\text { dart out in the same lane. }\end{array}$ & $\mathrm{HP}$ & 18 & 29 & 47 & 56.3 & 80.6 & 69.1 & 4.689 & 0.030 & 0.263 \\
\hline & h2-3 & $\begin{array}{c}\text { There may be a pedestrian } \\
\text { on the left between the bus } \\
\text { and the sidewalk. }\end{array}$ & $\mathrm{PH}$ & 6 & 22 & 28 & 18.8 & 61.1 & 41.2 & 12.551 & 0.000 & 0.430 \\
\hline & h2-4 & $\begin{array}{l}\text { Pedestrian is standing the } \\
\text { sidewalk. }\end{array}$ & $\mathrm{OH}$ & 10 & 1 & 11 & 31.3 & 2.8 & 16.2 & 10.128 & 0.001 & 0.386 \\
\hline Q3 & h3-3 & $\begin{array}{l}\text { Bicycle in the opposite } \\
\text { lane may dart out. }\end{array}$ & $\mathrm{HP}$ & 15 & 27 & 42 & 46.9 & 75.0 & 61.8 & 5.674 & 0.017 & 0.289 \\
\hline \multirow{2}{*}{ Q4 } & h4-1 & $\begin{array}{l}\text { Pedestrian may hide } \\
\text { behind the vehicle of } \\
\text { opposite lane. }\end{array}$ & $\mathrm{PH}$ & 18 & 30 & 48 & 56.3 & 83.3 & 70.6 & 5.985 & 0.014 & 0.297 \\
\hline & h4-4 & $\begin{array}{c}\text { Poor visibility because of } \\
\text { rain. }\end{array}$ & $\mathrm{OH}$ & 11 & 5 & 16 & 34.4 & 13.9 & 23.5 & 3.951 & 0.047 & 0.241 \\
\hline Q5 & h5-3 & $\begin{array}{l}\text { Bicycle in the left side may } \\
\text { dart out. }\end{array}$ & $\mathrm{HP}$ & 9 & 21 & 30 & 28.1 & 58.3 & 44.1 & 6.271 & 0.012 & 0.304 \\
\hline Q7 & h7-5 & $\begin{array}{l}\text { Fallen objects may come } \\
\text { from a construction site. }\end{array}$ & $\mathrm{PH}$ & 2 & 10 & 12 & 6.3 & 27.8 & 17.6 & 5.402 & 0.020 & 0.282 \\
\hline Q8 & h8-5 & $\begin{array}{l}\text { The opposite vehicle is } \\
\text { likely to overtake the } \\
\text { stopping taxi at the } \\
\text { opposite traffic lane. }\end{array}$ & $\mathrm{HP}$ & 3 & 13 & 16 & 9.4 & 36.1 & 23.5 & 6.730 & 0.009 & 0.315 \\
\hline Q10 & h10-9 & $\begin{array}{c}\text { The vehicle of right side at } \\
\text { the intersection are } \\
\text { waiting to turn left. }\end{array}$ & $\mathrm{OH}$ & 0 & 6 & 6 & 0.0 & 16.7 & 8.8 & $\begin{array}{c}3.961 \\
\mathrm{a}\end{array}$ & 0.047 & 0.241 \\
\hline \multirow{2}{*}{ Q11 } & h11-3 & $\begin{array}{l}\text { There is a motor vehicle at } \\
\text { the opposite traffic lane. }\end{array}$ & $\mathrm{OH}$ & 16 & 28 & 44 & 50.0 & 77.8 & 64.7 & 5.724 & 0.017 & 0.290 \\
\hline & h11-5 & $\begin{array}{l}\text { Pedestrian may run out } \\
\text { into the street from the } \\
\text { park }\end{array}$ & $\mathrm{PH}$ & 0 & 6 & 6 & 0.0 & 16.7 & 8.8 & $\begin{array}{c}3.961 \\
\mathrm{a}\end{array}$ & 0.047 & 0.241 \\
\hline \multirow[t]{2}{*}{ Q12 } & h12-2 & $\begin{array}{l}\text { Motorcycles is } \\
\text { approaching near the } \\
\text { vehicle from the rear on } \\
\text { the right side }\end{array}$ & $\mathrm{HP}$ & 19 & 33 & 52 & 59.4 & 91.7 & 76.5 & 9.818 & 0.002 & 0.380 \\
\hline & h12-4 & $\begin{array}{l}\text { Pedestrian may dart out } \\
\text { from left side. }\end{array}$ & $\mathrm{PH}$ & 7 & 18 & 25 & 21.9 & 50.0 & 36.8 & 5.764 & 0.016 & 0.291 \\
\hline \multirow{2}{*}{ Q13 } & h13-4 & $\begin{array}{l}\text { Pedestrian may dart out } \\
\text { from behind the truck. }\end{array}$ & $\mathrm{PH}$ & 5 & 16 & 21 & 15.6 & 44.4 & 30.9 & 6.592 & 0.010 & 0.311 \\
\hline & h13-5 & Bus is stopping in the side. & $\mathrm{OH}$ & 11 & 5 & 16 & 34.4 & 13.9 & 23.5 & 3.951 & 0.047 & 0.241 \\
\hline \multirow{2}{*}{ Q15 } & h15-1 & $\begin{array}{l}\text { There is a motor vehicle } \\
\text { running ahead. }\end{array}$ & $\mathrm{OH}$ & 26 & 36 & 62 & 81.3 & 100.0 & 91.2 & $\underset{\mathrm{a}}{5.256}$ & 0.022 & 0.278 \\
\hline & h15-3 & $\begin{array}{l}\text { Pedestrian may dart out in } \\
\text { the right/left side. }\end{array}$ & $\mathrm{PH}$ & 6 & 17 & 23 & 18.8 & 47.2 & 33.8 & 6.136 & 0.013 & 0.300 \\
\hline
\end{tabular}

HE: hazardous event number, HT: hazard type, NV: novice group, EX: experienced group, OH: obvious hazard, PH: potential hazard, HP: hazard prediction, a: Yates' correction.

\subsection{Comparing the Hazard Type in Each Group}

Comparing the three hazard types using the chi-square test within each group, there was a significant difference in both groups (novice: $\chi^{2}(2)=29.862, p=0.000$, experienced: $\left.X^{2}(2)=15.792, p=0.000\right)$. As a result of the residual analysis, novice drivers appeared to identify HP more than hazards in other categories, and they were not likely to identify PH. On the other hand, experienced drivers appeared to identify HP, unlike the difficulty in identifying $\mathrm{OH}$. 


\subsection{Comparing SSQ between Young and Middle Groups}

The median SSQ score was a low value, five in all subjects. The SSQ scores of men $(\mathrm{Mdn}=5)$ were the same as those of females $(\mathrm{Mdn}=5)$. A Mann-Whitney U test indicated that there was no significant difference between them $\left(U\left(N_{\text {male }}=37, N_{\text {female }}=31\right)=540.000\right.$, $\mathrm{z}=-0.414, p=0.679)$. Additionally, the SSQ scores of the novice group $(\mathrm{Mdn}=6)$ appeared to be similar to the experienced group $(\mathrm{Mdn}=4)$. A Mann-Whitney $\mathrm{U}$ test indicated that there was no significant difference $\left(\mathrm{U}\left(\mathrm{N}_{\text {novice }}=32, \mathrm{~N}_{\text {experienced }}=36\right)=653.000, \mathrm{z}=0.95\right.$, $p=0.239$ ).

\section{Discussion}

All the hazards were classified into three types $(\mathrm{OH}, \mathrm{PH}, \mathrm{HP})$. Subjects in this study experienced difficulty in classifying the hazard types through the touch screen, so the subjects were asked to answer each question verbally. In addition, the subjects' response about PH and HP types indicates that the method, which was developed based on situation awareness theory, is appropriate for this developmental study. Furthermore, our results appear to be consistent with previous study findings which indicated the following: the experienced drivers identified the hazardous events more than the novice drivers $[6,8,35]$; the novice drivers were able to identify visible hazards without having sufficient perception of potential hazards, whereas the experienced drivers paid attention to more potential hazards [13,34,35]; the novice drivers identified traffic hazards with low risk, whereas the experienced drivers understood the serious risks $[34,40]$. As the experienced drivers appeared to pay more attention to predictable hazards such as Level 3 of situation awareness theory, our results also appear to follow situation awareness theory.

These results suggest that the hazard perception test using VR is reasonably useful for gathering the characteristics of novice and experienced drivers. The sample size seems to be low, but we calculated it by power analysis, and the result of the phi coefficient $(0.2-0.4)$ indicated a medium effect size. Therefore, we consider these results to be reliable.

Previous hazard perception tests used one-screen or three-screen monitors, limiting users' visual field $[6,8,9,11-13,33-36]$. In terms of situation awareness theory [15,16], the hazard perception test needs to be conducted in the actual driving situation due to its requirement of reproducing the visual field of actual driving. Our study finding shows that utilizing the 360-degree visual field characteristics of VR allowed us to identify two unique hazards, classified as HP. In terms of the used screen hazard perception test, the participants were not able to identify the hazards without rotating their neck and trunk, like with driving, except when using a special screen such as CAVE. This finding suggests that the use of VR might impact situation awareness. Confirmation through the actual driving situation is often important from the perspective of rehabilitation dealing with physical and cognitive disabilities. The study from Carlozzi et al. [41] examined the difference in driving practice among patients with spinal cord injury by comparing the use of a normal three-screen monitor and a driving simulator. This study concluded that the use of an HMD provided a more similar driving situation compared to the other one in terms of the longer pausing time in the HMD group. We hypothesize that the longer pausing time helped the subjects confirm the hazards thoroughly using the HMD.

In regard to cybersickness, a few subjects had some cybersickness. However, no subjects dropped out from this study, and the median SSQ was 4 to 6, which was considered a low score. A previous study about driving simulation using an HMD reported that the average SSQ score was 30.91 [19]. In addition, another study with four types of transportation simulator using an HMD showed that the average SSQ value was at least 10.0 or more for all types [42]. Our results show that the SSQ could be kept low and that the hazard perception test by VR caused less cybersickness than the previous research results.

One of the reasons why the SSQ score is low is that it did not involve operations like a driving simulator. The mismatching between the past experience and the current multiple sensory inputs causes conflict and cybersickness [25]. A previous study in a VR driving simulator revealed that drivers are more likely to get cybersickness than non-drivers [43]. 
This result supports the mismatch between the driving experience and the simulated driving operation sensation which causes cybersickness. Sensory conflict theory explains that sensory conflicts can arise when the sensory information is not the stimulus that the subject expected based on the experience [28]. In the driving simulator case, a subject is required to operate the virtual motor vehicle but cannot gain the expected sensory input (e.g., the acceleration of gravity from braking or steering) [29]. Therefore, virtual operation of a motor vehicle may increase the opportunity for sensory conflict.

Our finding suggests that the main reason the participants experienced reduced cybersickness could be because they experienced driving through viewing a video rather than operating through the simulator. The use of video in driving could have minimized the risk of causing a conflict of multiple sensory inputs. Therefore, this study could suggest that cybersickness was reduced by avoiding multiple sensory input conflicts by viewing a simple video without operating the simulator.

Furthermore, cybersickness was found to be related to the duration of the implementation time. Previous studies showed that some participants experienced increased cybersickness with the increased duration of use [44], and others experienced increased cybersickness after a certain period of participation [45]. A systematic review also supported the notion that cybersickness is mainly increased with increased VR exposure time, and the study suggested administering VR for a short duration [24]. Previous studies support these results in that a longer exposure time would stimulate vection more and cause increased cybersickness [29-31]. This study provided the following time structure: 14 min of the VR exposure time; $20 \mathrm{~s}$ of showing the image in each question; and $5 \mathrm{~s}$ of posing time between each question. Optical flow did not occur when the static image was showing. This means that the risk of cybersickness was minimized in this study by considering a relationship between optical flow and cybersickness [30-32]. Although a previous study revealed that VR contents in driving rehabilitation are still limited and have limited usability due to their risk of causing cybersickness [24], our findings suggest that the use of edited video could help reduce cybersickness. This supports our study methodology to conduct the hazard perception test and increase usability. In addition, a study has shown that high-quality images could also reduce cybersickness [18]. However, simulators that can produce high-quality and substantial computerized video are often high in price, which has been a barrier to implementation in a rehabilitation setting $[13,46]$. Although there may be other methods of reducing cybersickness, this study proved the reduced influence of cybersickness by contriving one of the new methods, and this finding is expected to be useful to be applied by considering its cost-effectiveness.

From these facts, this study is the first study to suggest the usefulness of the hazard perception test by VR as a new possibility of automobile driving evaluation in the field of rehabilitation. Since there are not many studies using VR with an HMD in the driving rehabilitation field, the results of this study show that less cybersickness could be useful in future studies.

\section{Limitation}

Hazard scenarios in this study were made from actual driving. Therefore, we could not collect many serious dangerous hazards because we did not have the opportunity to meet that situation due to ethical problems. This could be a limitation of this study.

\section{Conclusions and Future Research}

The purpose of this study was to investigate differences in the hazard perception and cybersickness experienced between novice and experienced drivers measured in a VR HMD. This study conducted the new hazard perception test under an actual driving situation using an HMD. We conducted the hazard perception test by using situation awareness theory and the WWW format. This study shows the following findings: (i) all hazardous events were classified into three types $(\mathrm{OH}, \mathrm{PH}, \mathrm{HP})$; (ii) the experienced driver group identified more hazards than the novice group, as in the results of previous 
studies; (iii) the experienced drivers tended to identify the potential and predictive hazards more than the novices, as in the results of previous studies; (iv) there were two hazards which can only be detected by using the HMD; (iv) low SSQ scores of the participants, indicating less experience of cybersickness. These results might gain from minimizing the sensory conflict by editing the video, which included a sufficient resting time. Existing hazard perception tests using non-HMD devices have been discussed concerning their limitation in the user's visual field. However, this study that used an HMD addressed this limitation and detected two hazards that were not detected through the non-HMD devices. This method, which follows situation awareness theory, would be a novel method for the hazard perception test. Therefore, the main conclusion of this article is that an HMD with VR has a strong potential to be used as an empirical research tool in psychological and architectural research, and that future studies could supplement behavioral validation.

In future study, we will exclude some scenarios such as those not consistently identified by the subjects because the extended test time may increase cybersickness. We will then plan to develop the methodology of hazard detection using virtual pointing or eye tracking. A combination with video effects through augmented reality (e.g., a child hidden behind the vehicle) will be added in future research targeting healthy people first. We are aiming to compare the hazard type and reaction time between healthy subjects and stroke patients after the development of our hazard perception test.

Supplementary Materials: The following (Supplementary files A, B and Video S1) are available online on: https://www.mdpi.com/article/10.3390/electronics10091114/s1.

Author Contributions: Conceptualization, T.S., H.U., A.S., K.T., and Y.F.; methodology, T.S., H.U., A.S., and Y.F.; software, T.S., A.S., and H.I.; validation, K.T., K.O., Y.O., and Y.F.; formal analysis, T.S., H.U., K.T., K.O., and Y.F; investigation, T.S., H.U., A.S., and H.I.; resources, T.S., H.U., and K.O.; data curation, K.O. and Y.O.; writing — original draft preparation, T.S.; writing — review and editing, T.S., H.U., K.T., K.O., and Y.F.; visualization, T.S., A.S., and H.I.; supervision, K.T. and Y.F.; project administration, T.S.; funding acquisition, T.S. All authors have read and agreed to the published version of the manuscript.

Funding: This research was funded by the Grant-in-Aid for Scientific Research (C), grant number 70434529 .

Data Availability Statement: Raw data are available at https://www.mdpi.com/article/10.3390 /electronics10091114/s1 (access on 8 May 2021) by contacting the corresponding author, but the explanations of scenarios are in Japanese.

Acknowledgments: We thank Koji Mikami (VR and HMD technology) and Kaori Shinbo (data sampling) for their cooperation and useful advice.

Conflicts of Interest: The authors declare no conflict of interest.

\section{References}

1. Marshall, S.C.; Molnar, F.; Man-Son-Hing, M.; Blair, R.; Brosseau, L.; Finestone, H.M.; Lamothe, C.; Korner-Bitensky, N.; Wilson, K.G. Predictors of driving ability following stroke: A systematic review. Top. Stroke Rehabil. 2007, 14, 98-114. [CrossRef]

2. Reger, M.A.; Welsh, R.K.; Watson, G.S.; Cholerton, B.; Baker, L.D.; Craft, S. The Relationship Between Neuropsychological Functioning and Driving Ability in Dementia: A Meta-Analysis. Neuropsychology 2004, 18, 85-93. [CrossRef] [PubMed]

3. Hird, M.A.; Egeto, P.; Fischer, C.E.; Naglie, G.; Schweizer, T.A. A Systematic Review and Meta-Analysis of On-Road Simulator and Cognitive Driving Assessment in Alzheimer's Disease and Mild Cognitive Impairment. J. Alzheimer's Dis. 2016, 53, 713-729. [CrossRef]

4. Horswill, M.S.; McKenna, F.P. Drivers' Hazard Perception Ability: Situation Awareness on the Road. A Cognitive Approach to Situation Awareness: Theory and Application; Banbury, S., Tremblay, S., Eds.; Ashgate Publishing: New York, NY, USA, 2004 ; pp. 155-175.

5. Peltz, D.C.; Krupat, E. Caution profile and driving record of undergraduate males. Accid. Anal. Prev. 1974, 6, 45-58. [CrossRef]

6. Borowsky, A.; Shinar, D.; Oron-Gilad, T. Age, skill, and hazard perception in driving. Accid. Anal. Prev. 2010, 42, 1240-1249. [CrossRef] [PubMed]

7. Finn, P.; Bragg, B.W. Perception of the risk of an accident by young and older drivers. Accid. Anal. Prev. 1986, 18, 289-298. [CrossRef] 
8. Underwood, G.; Phelps, N.; Wright, C.; Van Loon, E.; Galpin, A. Eye fixation scanpaths of younger and older drivers in a hazard perception task. Ophthalmic Physiol. Opt. 2005, 25, 346-356. [CrossRef]

9. Wetton, M.A.; Hill, A.; Horswill, M.S. The development and validation of a hazard perception test for use in driver licensing. Accid. Anal. Prev. 2011, 43, 1759-1770. [CrossRef]

10. Moran, C.; Bennett, J.M.; Prabhakharan, P. Road user hazard perception tests: A systematic review of current methodologies Accid. Anal. Prev. 2019, 129, 309-333. [CrossRef]

11. Anstey, K.J.; Eramudugolla, R.; Huque, H.; Horswill, M.; Kiely, K.; Black, A.; Wood, J. Validation of Brief Screening Tools to Identify Impaired Driving Among Older Adults in Australia. JAMA Netw. Open 2020, 3, e208263. [CrossRef]

12. Bowers, A.R.; Mandel, A.J.; Goldstein, R.B.; Peli, E. Driving with Hemianopia, I: Detection Performance in a Driving Simulator. Investig. Opthalmol. Vis. Sci. 2009, 50, 5137-5147. [CrossRef]

13. Sasaki, T.; Nogawa, T.; Yamada, K.; Kojima, T.; Kanaya, K. Hazard perception of stroke drivers in a video-based Japanese hazard perception task. Traffic Inj. Prev. 2019, 20, 264-269. [CrossRef]

14. Endsley, M. Situation awareness global assessment technique (SAGAT). In Proceedings of the IEEE 1988 National Aerospace and Electronics Conference, Dayton, OH, USA, 23-27 May 1988; Volume 3, pp. 789-795.

15. Endsley, M.R. Toward a Theory of Situation Awareness in Dynamic Systems. Hum. Factors J. Hum. Factors Ergon. Soc. 1995, 37, 32-64. [CrossRef]

16. Slater, M.; Usoh, M.; Steed, A. Depth of Presence in Virtual Environments. Presence Teleoperators Virtual Environ. 1994, 3 , 130-144. [CrossRef]

17. Slater, M.; Wilbur, S. A framework for immersive virtual environments (FIVE): Speculations on the role of presence in virtual environments. Presence Teleoperators Virtual Environ. 1997, 6, 603. [CrossRef]

18. Agrawal, R.; Knödler, M.; Fisher, D.L.; Samuel, S. Virtual Reality Headset Training: Can It Be Used to Improve Young Drivers' Latent Hazard Anticipation and Mitigation Skills. Transp. Res. Rec. J. Transp. Res. Board 2018, 2672, 20-30. [CrossRef]

19. Madigan, R.; Romano, R. Does the use of a head mounted display increase the success of risk awareness and perception training (RAPT) for drivers? Appl. Ergon. 2020, 85, 103076. [CrossRef] [PubMed]

20. Psotka, J. Immersive training systems: Virtual reality and education and training. Instr. Sci. 1995, 23, 405-431. [CrossRef]

21. Schultheis, M.T.; Mourant, R.R. Virtual Reality and Driving: The Road to Better Assessment for Cognitively Impaired Populations. Presence Teleoperators Virtual Environ. 2001, 10, 431-439. [CrossRef]

22. Yamani, Y.; Biçaksiz, P.; Palmer, D.B.; Cronauer, J.M.; Samuel, S. Following expert's eyes: Evaluation of the effectiveness of a gaze-based training intervention on young drivers' latent hazard anticipation skills. In Proceedings of the Ninth International Driving Symposium on Human Factors in Driver Assessment, Training and Vehicle Design 2017, Manchester Village, VT, USA, 26-29 June 2017.

23. Blane, A.; Lee, H.C.; Falkmer, T.; Willstrand, T.D. Assessing Cognitive Ability and Simulator-Based Driving Performance in Poststroke Adults. Behav. Neurol. 2017, 2017, 1-9. [CrossRef]

24. Classen, S.; Bewernitz, M.; Shechtman, O. Driving Simulator Sickness: An Evidence-Based Review of the Literature. Am. J. Occup. Ther. 2011, 65, 179-188. [CrossRef]

25. Weidner, F.; Hoesch, A.; Poeschl, S.; Broll, W. Comparing VR and non-VR driving simulations: An experimental user study. In Proceedings of the 2017 IEEE Virtual Reality (VR), Los Angeles, CA, USA, 18-22 March 2017; pp. $281-282$.

26. Aykent, B.; Yang, Z.; Merienne, F.; Kemeny, A. Simulation sickness comparison between a limited field of view virtual reality head mounted display (Oculus) and medium range field of view static ecological driving simulator (eco2). Proc. Driv. Simul. Conf. 2016, 31, 31 .

27. Dużmańska, N.; Strojny, P.; Strojny, A. Can Simulator Sickness Be Avoided? A Review on Temporal Aspects of Simulator Sickness. Front. Psychol. 2018, 9, 2132. [CrossRef]

28. Reason, J.T. Motion sickness adaptation: A neural mismatch model. J. R. Soc. Med. 1978, 71, 819-829. [CrossRef] [PubMed]

29. Laviola, J.J. A discussion of cybersickness in virtual environments. ACM SIGCHI Bull. 2000, 32, 47-56. [CrossRef]

30. Kennedy, R.S.; Hettinger, L.J.; Lilienthal, M.G. Simulator Sickness. Motion and Space Sickness; Crampton, G.H., Ed.; CRC Press: Boca Raton, FL, USA, 1988; pp. 317-341.

31. McCauley, M.E.; Sharkey, T.J. Cybersickness: Perception of Self-Motion in Virtual Environments. Presence Teleoperators Virtual Environ. 1992, 1, 311-318. [CrossRef]

32. Moss, J.D.; Muth, E.R. Characteristics of Head-Mounted Displays and Their Effects on Simulator Sickness. Hum. Factors J. Hum. Factors Ergon. Soc. 2011, 53, 308-319. [CrossRef] [PubMed]

33. Crundall, D. Hazard prediction discriminates between novice and experienced drivers. Accid. Anal. Prev. 2016, 86, 47-58. [CrossRef]

34. Renge, K. Drivers' hazard and risk perception, confidence in safe driving, and choice of speed. IATSS Res. 1998, 22, 103-110.

35. Crundall, D.; Chapman, P.; Trawley, S.; Collins, L.; Van Loon, E.; Andrews, B.; Underwood, G. Some hazards are more attractive than others: Drivers of varying experience respond differently to different types of hazard. Accid. Anal. Prev. 2012, 45, 600-609. [CrossRef]

36. Borowsky, A.; Oron-Gilad, T. Exploring the effects of driving experience on hazard awareness and risk perception via real-time hazard identification, hazard classification, and rating tasks. Accid. Anal. Prev. 2013, 59, 548-565. [CrossRef] 
37. Grayson, G.B.; Sexton, B.F. The Development of Hazard Perception Testing. TRL Report 2002, 558. Available online: https: // trid.trb.org/view/731829 (accessed on 7 May 2021)

38. Ventsislavova, P.; Crundall, D. The hazard prediction test: A comparison of free-response and multiple-choice formats. Saf. Sci. 2018, 109, 246-255. [CrossRef]

39. Kennedy, R.S.; Lane, N.E.; Berbaum, K.S.; Lilienthal, M.G. Simulator Sickness Questionnaire: An Enhanced Method for Quantifying Simulator Sickness. Int. J. Aviat. Psychol. 1993, 3, 203-220. [CrossRef]

40. Benda, H.V.; Hoyos, C.G. Estimating hazards in traffic situations. Accid. Anal. Prev. 1983, 15, 1-9. [CrossRef]

41. Carlozzi, N.E.; Gade, V.; Rizzo, A. "Skip"; Tulsky, D.S. Using virtual reality driving simulators in persons with spinal cord injury: Three screen display versus head mounted display. Disabil. Rehabil. Assist. Technol. 2012, 8, 176-180. [CrossRef] [PubMed]

42. Aldaba, C.N.; White, P.J.; Byagowi, A.; Moussavi, Z. Virtual reality body motion induced navigational controllers and their effects on simulator sickness and pathfinding. In Proceedings of the 2017 39th Annual International Conference of the IEEE Engineering in Medicine and Biology Society (EMBC), Jeju, Korea, 11-15 July 2017; Volume 2017, pp. 4175-4178.

43. Stoffregen, T.A.; Chang, C.-H.; Chen, F.-C.; Zeng, W.-J. Effects of decades of physical driving on body movement and motion sickness during virtual driving. PLoS ONE 2017, 12, e0187120. [CrossRef]

44. Sinitski, E.; Thompson, A.; Godsell, P.; Honey, J.; Besemann, M. Postural stability and simulator sickness after walking on a treadmill in a virtual environment with a curved display. Displays 2018, 52, 1-7. [CrossRef]

45. Feenstra, P.; Bos, J.; Van Gent, R. A visual display enhancing comfort by counteracting airsickness. Displays 2011, 32, 194-200. [CrossRef]

46. Sportillo, D.; Paljic, A.; Ojeda, L. Get ready for automated driving using Virtual Reality. Accid. Anal. Prev. 2018, 118, 102-113. [CrossRef] [PubMed] 